\title{
O que aprendi com Sílvio Coelho dos Santos
}

\section{Ruben George Oliven}

Pesauısador CNPq / Unıversıdade Federal do Rı Grande do Sul Porto Alegre Brasıl ruben oliven@pq cnpqbr

Conhecı Sílvıo Coelho dos Santos em 1973, no Museu Nacional
numa reunıão de um grupo de trabalho encarregado pelo CNPq de avalıar a sıtuação de pesquısa e pós-graduação em Antropologıa, Ciêncıa Polıtıca e Socıologıa no Brasıl Sımpatızeı imedıatamente com ele pelo seu jeito afetivo e franco A partır dai for se desenvolvendo uma amızade que perdura até hoje Interagımos nas mass variadas atıvidades profissionais e convivemos socialmente, o que inclui nossas respectivas esposas E, portanto, com multo prazer, que partıcipo de um número de Ilha que homenagela a grande figura que Silvo e

Sulvio Coelho dos Santos tem dado uma contribuıção fundamental à Antropologıa brasıleira Isso ocorre através de suas pesquisas de sua atıvıdade docente e também de sua atıvıdade instıtucional Ele desenvolveu várıos estudos sobre populações indígenas, tendo uma vasta produção nessa area Minıstrou numerosos cursos e orıentou muitos alunos Do ponto de vista institucional, Silvio teve um papel decisivo no desenvolvimento de Unıversıdade Federal de Santa Ca tarına, tendo sıdo um dos criadores do Museu de Antropologı dessa universidade Ele for pro-reitor de Ensino da UFSC num momento em que ela expandıu seus cursos Junto com seus colegas, Sılvıo 
criou o Programa de Pos-Graduação em Antropologia Social dessa unıversıdade, um curso que esta entre os melhores do Brasıl Ele tambem fol um dos primeiros presıdentes da Assocıação Brasıleıra de Antropologıa que não é do eıxo São Paulo-Rı-Brasılıa, tendo tıdo uma notável atuação durante sua gestão

Seguindo seus passos, fuı presıdente da ABA no bıênıo 2000-2002 Embora apenas uma pequena parcela dos antropologos brasıleıros se dedıque a estudar grupos indígenas, a maıor parte da atıvidade polítıca da ABA dız respeito as questões indigenas Assım, e compreensıvel que uma das mais importantes comıssões de nossa associação seja justamente a de assuntos indigenas Sendo um antropólogo urbano, quando assumı a presıdêncıa de nossa assocıação del-me conta que precısava de alguem que pudesse me orıentar nessa questão Pedı a Sílvıo que ele presıdısse a Comıssão de Assuntos Indıgenas Eu sabıa que, alem de ser um nome consensual, ele alıa grande conhecimento do tema com profundo discernimento de questões polítıcas Tinha plena consciêncıa que estava pedındo a Sılvıo algo que exıge muıto trabalho, mas era pela causa, como se diz no nosso meı Para felicldade minha e da ABA, Sılvio aceitou e ele passou a ser meu mentor no que diz respeito a essas questões

Criada em 1955, a Associação Brasuleura de Antropologia e uma das mals antigas sociedades científicas brasileiras Historicamente, a ABA tem se pautado por três compromissos fundamentaıs o respeıto pela dıversıdade de posıções cientıfıcas entre seus assocıados, a serıedade de suas atıvidades acadêmicas e o compromisso intransıgente com populações com as quaıs a Associação esta envolvida, por meıo de pesquisas ou de intervenções sociaıs sociedades indıgenas, comunıdades remanescentes de quulombos diferentes munorias e grupos vulneráveıs da socıedade brasıleıra A ABA e, portanto, uma assocıação suı generıs ela é ao mesmo tempo cientıfica, profıssional e envolvida com causas públicas São essas diferentes faces que compõem sua singularıdade

Como associação cientıfica, a ABA e um lugar de dissenso onde convivem diferentes formas de fazer antropologia e de interpretar dados Isso transparece nas reuniões brasıleiras de Antropologia e nos semınarıos que a assocıação promove Não há consenso nesses eventos, nem algum paradıgma que seja consıderado oficıal Por outro lado, 
sendo uma assocıação profıssıonal a ABA e multo peculıar Não sendo a profissão de antropologo regulamentada, ser socıo efetıvo da $\mathrm{ABA}$ sıgnifica, na prátıca, ser reconhecıdo pelos pares como antropologo $\mathrm{A}$ Assocıação tem regras claras para aceitar alguem como sócıo efetıvo Ele precısa ter no minumo a tıtulação de mestre em Antropologıa ou uma produção cıentıfıca equivalente

A face da incidência públıca da ABA é tambem muito singular Tradicionalmente, ele tem se envolvido com causas ligadas aos grupos que seus associados estudam Inıcialmente, estes eram os povos indigenas A medida que os antropólogos começaram a amplıar seus objetos de estudos, o envolvimento da ABA tambem começou a se alargar e a incluir os remanescentes de comunidades quilombos e outros grupos em situações de vulnerabilıdade

O crescente envolvimento publico da ABA umplicou a criação de comussões permanentes e de grupos de trabalho que assessoram a diretorıa comıssão de assuntos indıgenas, comıssão de direıtos humanos e comıssão de relações etnıcas e racıaıs A ABA ja teve um grupo de trabalho sobre laudos antropologicos e atualmente tem um grupo de trabalho sobre qulombos

A questão dos direitos humanos sempre esteve, portanto presente, no horızonte de atuação da ABA Isso tem sıdo sua pratıca não somente em perıodos de repressão, mas também em situações de normalıdade democratıca Durante a elaboração da atual Constıtulção Federal, a ABA partıcıpou atıvamente junto aos parlamentares no capitulo sobre as populações indigenas No mesmo período, ela assinou um protocolo com a Procuradoria Geral da Republica, que em 2002, foı transformado em convênıo Através desse documento, a ABA colabora com o Mınısterıo Publıco Federal na realızação de laudos antropologicos periciaıs que permitam subsıdıar e apoiar tecnicamente os trabalhos do Minıstérıo Publico Federal nas questões que envolvam direıtos e interesses de populações indıgenas, remanescentes de quilombos, grupos etnicos e minorias Sempre que solicitada, a ABA indica um de seus sócıos especialısta no grupo em quєstão

De acordo com a Constıtuıção Brasıleıra, cabe a Procuradona Geral da Repúblıca a defesa da ordem jurıdıca do regıme democrátıco e dos interesses socıaıs e indıvıduais undısponıveıs o convênı que 
a ABA mantém com ela sıgnıfica uma alıança com uma instıtuıção vocacionada e qualıficada para atuar na defesa de grupos que tradlclonalmente estudamos e com cujos direitos estamos comprometıdos Juızes tambem costumam solıcıtar à ABA a indıcação de socıos para a elaboração de laudos, o que prova que operadores do Dureıto consıderam os membros da Associação antropólogos credenciados

Um exemplo do crescente envolvimento da ABA com questões públicas se refere a seu compromisso com a questão dos dıreitos das comunidades de remanescentes dos quilombos em Alcântara Em 200I, a Assocıação indıcou um de seus sócıos para realızar pencia antropológıca que permitısse a ıdentıfıcação das comunıdades de remanescentes de quilombos e as suas respectıvas localızações nas proxımıdades da área do Centro de Lançamento de Alcântara Ao mesmo tempo, a Assocıação entabulou negociações com a Amerıcan Anthropologıcal Assocıatıon, solıcıtando que esta se durigısse ao governo norte-amerıcano sobre a questão da violação de direitos humanos das comunıdades remanescentes de quılombo atıngıdas pelo Centro de Lançamento de Alcântara, tendo em vista a assunatura do Acordo de Salvaguardas Tecnológıcas firmado entre o Brasıl e os Estados Unıdos Como consequêncıa dessa carta, o presıdente da AAA envıou correspondêncıa ao secretárıo de estado norte-amerıcano, solıcitando esclarecimentos e providências Nesse processo fol fundamental a exıstêncıa de assocıados com conhecumento da problematıca, competêncıa para realızar perícıas antropologıcas e elaborar laudos, e capacıdade de artıculação e contatos unternacionals da ABA com associações congêneres

Para que atuação públıca da ABA seja eficıente é preciso que ela consıga dıalogar com os duferentes atores com que se relacıona No caso do campo jurídıco, é necessano um dıálogo entre doıs saberes dıferentes que devem encontrar uma sintonıa que produza resultados no campo jurídıco Queremos utılızar nosso saber antropologico de tal forma que ele beneficie aqueles grupos com os quais nos sentımos comprometıdos Ao elaborar perícias relatıvas ao reconhecumento de terras indígenas e de afrodescendentes, os antropólogos se valem de sua experıêncıa de trabalho de campo etnografıco Mas, ao redıgurem seus laudos, é precıso que eles se deem conta de que um laudo não é um documento para 
ser lıdo nos meıs acadêmicos, mas por juizes Assım é importante utllizar nosso treıno em relatıvizar discursos para produzır documentos que permıtam aos juızes formar convicções favoráveıs aos grupos que queremos ajudar Numa sociedade democrática, quem tem o poder legıtımo de decıdır sobre a demarcação de terras e o Judıcıáno

Se a ABA tem uma intensa interface com a sociedade, isto não sıgnifica, entretanto, que sua atuação se confunde com a de orgam zações não governamentaıs Ela é acıma de tudo uma assocıação de pesquisadores e profıssionais que, sendo respeitada pelo saber cientıfico que produz, e constantemente solıcıtada a intervir na esfera públıca Ela atua publicamente porque se sente comprometida com os grupos que pesquisa Sua legitımıdade decorre do fato de ela ser uma assocıação cientifica que, por sua serıedade, granjeou o respeito publico

Aprendı muıto do que está descrıto acıma com Sılvıo Mas acıma de tudo, ele me ensinou que a demarcação dos territórıos indígenas e a dos remanescentes de comunidades quilombolas envolvem uma dimensão etıca e moral Se não conseguirmos assegurar os dureitos das minorıas nosso Pais nunca sera uma sociedade plenamente democratica Por isso, reconhecer a posse das terras as sociedades indigenas e aos remanescentes de comunidades de quilombos não e uma questão que dız respeıto apenas a indıos e negros, mas a toda a sociedade brasıleira 